\title{
Hepatitis B specific T cell immunity induced by primary vaccination persists independently of the protective serum antibody level
}

\author{
Maria Carollo a,1, Raffaella Palazzo ${ }^{\mathrm{a}, 1}$, Manuela Bianco ${ }^{\mathrm{a}}$, Elisabetta Pandolfi ${ }^{\mathrm{b}}$, Paola Chionne ${ }^{\mathrm{a}}$, \\ Giorgio Fedele ${ }^{\mathrm{a}}$, Alberto Eugenio Tozzi ${ }^{\mathrm{b}}$, Rita Carsetti ${ }^{\mathrm{c}}$, Luisa Romanò ${ }^{\mathrm{d}}$, Clara Maria Ausiello ${ }^{\mathrm{a}, *}$ \\ a Anti-Infectious Immunity Unit, Department of Infectious, Parasitic and Immune-Mediated Diseases, Istituto Superiore di Sanità, Viale Regina Elena 299, Rome, Italy \\ ${ }^{\mathrm{b}}$ Epidemiology Unit, Research Center, Ospedale Pediatrico Bambino Gesù, IRCCS, Piazza S. Onofrio 4, 00165 Roma, Italy \\ ${ }^{c}$ Laboratory of Flow-Cytometry and B Cell Development, Research Center, Ospedale Pediatrico Bambino Gesù, IRCCS, Piazza S. Onofrio 4, 00165 Roma, Italy \\ ${ }^{\mathrm{d}}$ Department of Public Health, Microbiology, Virology, Università degli Studi di Milano, Via Pascal 36, Milan, Italy
}

\section{A R T I C L E I N F O}

\section{Article history:}

Received 23 August 2012

Received in revised form 6 November 2012

Accepted 8 November 2012

Available online 19 November 2012

\section{Keywords:}

Ag-specific blasts proliferation

Cytokines (IFN $\gamma$, IL-2)

Hepatitis vaccination

Hexavac $^{\circledR}$

Infanrix-hexa ${ }^{\circledR}$

$T$ cell responses

$\mathrm{T}$ memory subsets

\begin{abstract}
A B S T R A C T
In 2005, in accordance with recommendations made by the European Medicines Agency, the Italian

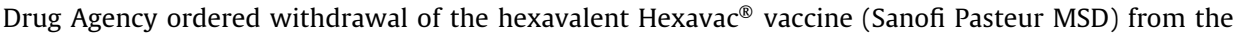
market. Concerns had been raised about the low immunogenicity of the hepatitis B virus component of the vaccine, assessed by measurement of serum antibody levels, and its potential consequences on longterm protection against hepatitis B infection. We evaluated memory $\mathrm{T}$ cell response to establish whether there are differences in the protective mechanisms among children who had received either Hexavac ${ }^{\circledR}$ or Infanrix-hexa ${ }^{\circledR}$ (GlaxoSmithKline) as their primary vaccination. Immunological memory was determined by measuring the ability of T cells to proliferate and secrete IFN $\gamma$ by ELISA and intracellular cytokines (IFN $\gamma$ and IL-2) when cultured with hepatitis B surface antigen (HBsAg). The different memory subsets of $T$ cells were also measured.

The results indicate that, although they generate different serum antibody levels, both vaccines are efficient in generating $T$ recall responses in vitro five years after the primary vaccination. The less immunogenic Hexavac ${ }^{\circledR}$ vaccine induces a strong $\mathrm{T}$ antigen response, as indicated by increased blast proliferation and the enhanced presence of memory subsets after HBsAg recall stimulation. These findings suggest that cellular immune response should be considered alongside serological markers as a surrogate of protection.
\end{abstract}

(c) 2012 Elsevier Ltd. All rights reserved.

\section{Introduction}

Viral hepatitis type B (HBV) is a major public health issue, accounting for high morbidity and mortality rates worldwide. Following acute infection with the HBV, between 1 and $10 \%$ of infected adults and 30-90\% of infected children become chronic carriers and may develop life-threatening diseases such as cirrhosis and primary hepatocellular carcinoma [1]. Whether the virus can be cleared or

Abbreviations: Ab, antibody; CM, central memory; EM, effector memory; $\mathrm{HB}$ hepatitis B; HBV, hepatitis B virus; HBsAg, hepatitis B surface antigen; FSC, forward scatter; ICS, intracellular staining; PBMC, peripheral blood mononuclear cells; SEM, standard error of the mean; SSC, side scatter; TD, terminally differentiated.

* Corresponding author at: Department of Infectious, Parasitic and ImmuneMediated Diseases, Anti-Infectious Immunity Unit, Istituto Superiore di Sanità, Viale Regina Elena 299, 00161 Rome, Italy. Tel.: +39 064990 2890; fax: +39 0649903168.

E-mail addresses: clara.ausiello@iss.it, ausiello@iss.it (C.M. Ausiello).

1 Equally contributed to the study. persists seems to depend largely on the vigour and specificity of the $\mathrm{T}$ cell response to the virus $[2,3]$.

Safe vaccines have been available since the early 1980s, proving effective in the prevention and control of hepatitis $\mathrm{B}(\mathrm{HB})$ and its long-term sequelae [4,5]. In 2001, two hexavalent vaccines Hexavac ${ }^{\circledR}$ (Hexavac)(Sanofi Pasteur MSD) and Infanrix-hexa ${ }^{\circledR}$ (Infanrix) (GlaxoSmithKline) against HB, tetanus, diphtheria, pertussis, poliomyelitis and Haemophilus influenzae type b were introduced in Italy. The hepatitis component consists in hepatitis B surface antigen (HBsAg) produced in yeast cells of Saccharomyces cervisiae by recombinant DNA technologies and adsorbed in Aluminium hydroxide. The protein content was 5 or $10 \mu \mathrm{g}$ dose in Hexavac or Infanrix vaccines, respectively. In 2005, in accordance with recommendations made by the European Medicines Agency, the Italian Drug Agency ordered the withdrawal of Hexavac due to concerns that the low antibody $(\mathrm{Ab})$ titres elicited by the vaccine in children might not provide adequate protection against HBV during adolescence and later in life, when vaccinated subjects are at greater risk of exposure to the virus [6,7]. Because Hexavac had 
been used in Italy to immunize approximately $50 \%$ of infants born in 2002-2004, a multicentre study was undertaken to investigate the serological response to a booster dose of $\mathrm{HB}$ vaccine 5 years after primary immunization [8].

Emerging evidence in a number of systems suggests that comprehensive qualitative assessment of immunologic memory may allow more accurate identification of protective mechanisms $[9,10]$. Further studies of a subgroup of children in the multicentre study [8] were therefore undertaken, to evaluate the immunological memory of $\mathrm{T}$ cells. Besides assessing Ag-specific proliferation and cytokine production, analyzing $\mathrm{T}$ memory subsets is an innovative approach to evaluating the role of $\mathrm{T}$ cell immunity induced by vaccination/infection [11]. Different subsets of T memory cells can be classified on the basis of their phenotype. Human central memory cells (CM) are CD45RO positive cells that constitutively express CCR7 and CD62L. These two receptors, which are required for cell extravasation through high endothelial venules and for migration to lymphoid organs, are also characteristic of naive $\mathrm{T}$ cells (CD45RA). T effector cells either become senescent terminally differentiated T cells (TD), dying by apoptosis soon after the pathogen is cleared, or differentiate into effector memory (EM) cells expressing low levels of CD62L and not expressing CCR7. Furthermore, $\mathrm{CM}$ are strongly proliferative, but have few effector functions, whereas EM produce effector cytokines, but have limited proliferative capacities [9-14].

To better define the protection mechanisms and identify potential problems with the Hexavac vaccine, we evaluated the persistence of $\mathrm{T}$ cell immunity five years after primary vaccination by assessing the HBsAg specific response measured as blast proliferation and IFN $\gamma$ secretion in culture supernatants. The quality of HBsAg specific T cell response was also characterized by the analysis of the frequency of CD4/CD8 cells secreting IFN $\gamma /$ IL-2, memory subsets and memory subsets secreting IFN $\gamma / \mathrm{IL}-2$. Increased proliferation and the overall enhanced presence of memory subsets following HBsAg recall stimulation indicate that Hexavac induces a consistent $\mathrm{T}$ antigen response.

\section{Materials and methods}

\subsection{Study population}

One hundred children belonging to cohorts of children receiving one of the two hexavalent vaccines - Hexavac $(n=66)$ and Infanrix $(n=34)$ - as their primary vaccination between 2002 and 2003, administered at 3, 5 and 11 months of age [8], were enrolled for assessment of $\mathrm{T}$ cell immune response (Table 1 ). All of the children had a properly completed vaccination schedule. A blood sample was collected from each of the participants upon enrolment in the study and HBsAg specific responses assessed. Discrepancies in the number of children enrolled and the data reported in the different assays are explained in Table 1 . The anti HB data, measured in the companion study on B memory response [15], are also shown in Table 1. Ethics approval was obtained from the ethics committee of the IRCCS Bambino Gesù, Rome, Italy, and written informed consent furnished by the children's parents or legal guardians.

\section{2. $\mathrm{HBs} A g$ specific immune response by blast proliferation, IFN $\gamma$ secretion, intracellular cytokine production and memory subset phenotypic analysis}

Peripheral blood mononuclear cells (PBMC) were isolated as described [16]. Cells were seeded into $5 \mathrm{ml}$ Falcon polystyrene tubes at a concentration of $5 \times 10^{5}$ cells $/ 500 \mu$ l in RPMI 1640 supplemented with antibiotics $(100 \mathrm{U} / \mathrm{ml}$ of penicillin, $0.1 \mu \mathrm{g} / \mathrm{ml}$ of streptomycin), $0.1 \mathrm{mM}$ non-essential amino acids, $1 \mathrm{mM}$ sodium pyruvate, $2 \mathrm{mM}$ L-glutamine and $25 \mathrm{mM}$ HEPES, all from Euroclone (Milan, Italy), 0.05 mM 2-mercaptoethanol (Sigma Chemical Co., St. Louis, MO, US) and supplemented with 10\% LPS-screened Foetal Bovine Serum (Hyclone Laboratories, South Logan, UT) (complete medium) [16]. PBMC were cultured at $37^{\circ} \mathrm{C}$ in a $5 \% \mathrm{CO}_{2}$ incubator in the presence of HBsAg $(10 \mu \mathrm{g} / \mathrm{ml}$, subtype AD batch PHBD1/03, $1 \mathrm{mg} / \mathrm{ml}$, Dia.Pro Diagnostic BioProbes Srl., Milan, Italy) or the appropriate negative (medium) or positive Staphylococcus Enterotoxin B $(0.5 \mu \mathrm{g} / \mathrm{ml})$ (Sigma) controls. After 6 days of culture, T cell proliferation was measured by enumerating blast cells identified by forward scatter (FSC) and side scatter (SSC), using flow-cytometry analysis as described in the paper by Carollo et al., where a precise comparison of the blast proliferation with the $3 \mathrm{H}$-thimidyme incorporation was performed and a good correlation of results with the two methods was obtained [17]. The gating strategy is shown in Fig. 1.

Supernatants were collected after 6 days to measure IFN $\gamma$ by specific ELISA (Quantikine, R\&D Systems, Minneapolis, MN). The lower detection limit was $8.0 \mathrm{pg} / \mathrm{ml}$. Optical density was measured using a 3550-UV Microplate Reader (BioRad, Philadelphia, PA) according to the manufacturer's instructions.

For intracellular cytokine and memory subset analysis, PBMC were seeded as described previously and cultured at $37{ }^{\circ} \mathrm{C}$ in a $5 \% \mathrm{CO}_{2}$ incubator for either 1 or 6 days. Co-stimulatory molecules [anti-CD28 and anti-CD49d $(1 \mu \mathrm{g} / \mathrm{ml}$; BD Biosciences)] were added to the 1 -day cultures $[18,19]$. In preliminary experiments, we found that at day 6 of cultures the addition of co-stimuli was not needed because it did not ameliorate the antigen specific response (data not shown and [20]). Brefeldin A $(5 \mu \mathrm{g} / \mathrm{ml}$, Sigma) was added during the last $4 \mathrm{~h}$ of culture. Cells were washed in PBS, fixed in $1 \mathrm{ml} 2 \%$ paraformaldehyde for $15 \mathrm{~min}$ and washed in staining buffer (PBS/Bovine Serum Albumin 0.5\%/Sodium Azide 0.02\%).

Cells were simultaneously stained for extracellular markers (CD4, CD8, CD45RA, CCR7) and intracellular cytokines (IFN $\gamma$ and IL-2), using mouse anti-human CD4-PerCP-Cy5.5, CD8-APC-Cy ${ }^{\mathrm{TM}} 7$, CD45RA-PE-Cy7, IFN $\gamma$ Alexa Fluor ${ }^{\circledR}$ 647, IL-2-FITC, and rat-antihuman CCR7-PE (clone CD197). Appropriate isotype matched controls were run in parallel. All monoclonal Abs were purchased from Becton Dickinson (Mountain View, CA) and appropriately

Table 1

Study population: base-line characteristic of the cohort.

\begin{tabular}{|c|c|c|c|c|c|c|c|c|}
\hline Vaccine used & $\begin{array}{l}\text { Number of } \\
\text { children } \\
\text { enrolled }\end{array}$ & $\begin{array}{l}\text { HBsAg } \\
\text { IFN } \gamma \text { ELISA }\end{array}$ & HBsAg blasts & $\begin{array}{l}\text { IFN } \gamma / \text { IL- } 2 \text { ICS and } \\
\text { memory subset } \\
1 \text { day }\end{array}$ & $\begin{array}{l}\text { IFN } \gamma / \text { IL- } 2 \text { ICS and } \\
\text { memory subset } \\
6 \text { day }\end{array}$ & $\begin{array}{l}\text { Anti-HB IgG } \\
(\mathrm{mIU} / \mathrm{ml}) \\
\text { Mean } \pm \text { SEM }\end{array}$ & $\begin{array}{l}\text { Anti-HB IgG } \\
\text { Positive } \\
\text { donors }^{\mathrm{a}}\end{array}$ & $\begin{array}{l}\mathrm{SEB}^{\mathrm{b}} \\
\text { IFN } \gamma \text { ELISA } \\
\text { Mean } \pm \text { SEM }\end{array}$ \\
\hline Hexavac & 66 & 66 & $62^{c}$ & 34 & $62^{c}$ & $\begin{array}{l}66 \\
22.7 \pm 6.4\end{array}$ & $\begin{array}{l}28 / 66 \\
(42 \%)\end{array}$ & $\begin{array}{l}66 \\
10,063 \pm 701\end{array}$ \\
\hline Infanrix & 34 & 34 & 34 & 34 & 34 & $\begin{array}{l}34 \\
136.7 \pm 37.5\end{array}$ & $\begin{array}{l}26 / 34 \\
(76 \%)\end{array}$ & $\begin{array}{l}34 \\
10,333 \pm 697\end{array}$ \\
\hline
\end{tabular}

\footnotetext{
a Percentage of children with anti-HBs IgG $>10(\mathrm{mIU} / \mathrm{ml})[8,15]$.

b Staphylococcus Enterotoxin B was used as positive control. Values from stimulated cultures minus values of unstimulated cultures are shown.

c 4 samples not assessed due to staining troubles.
} 

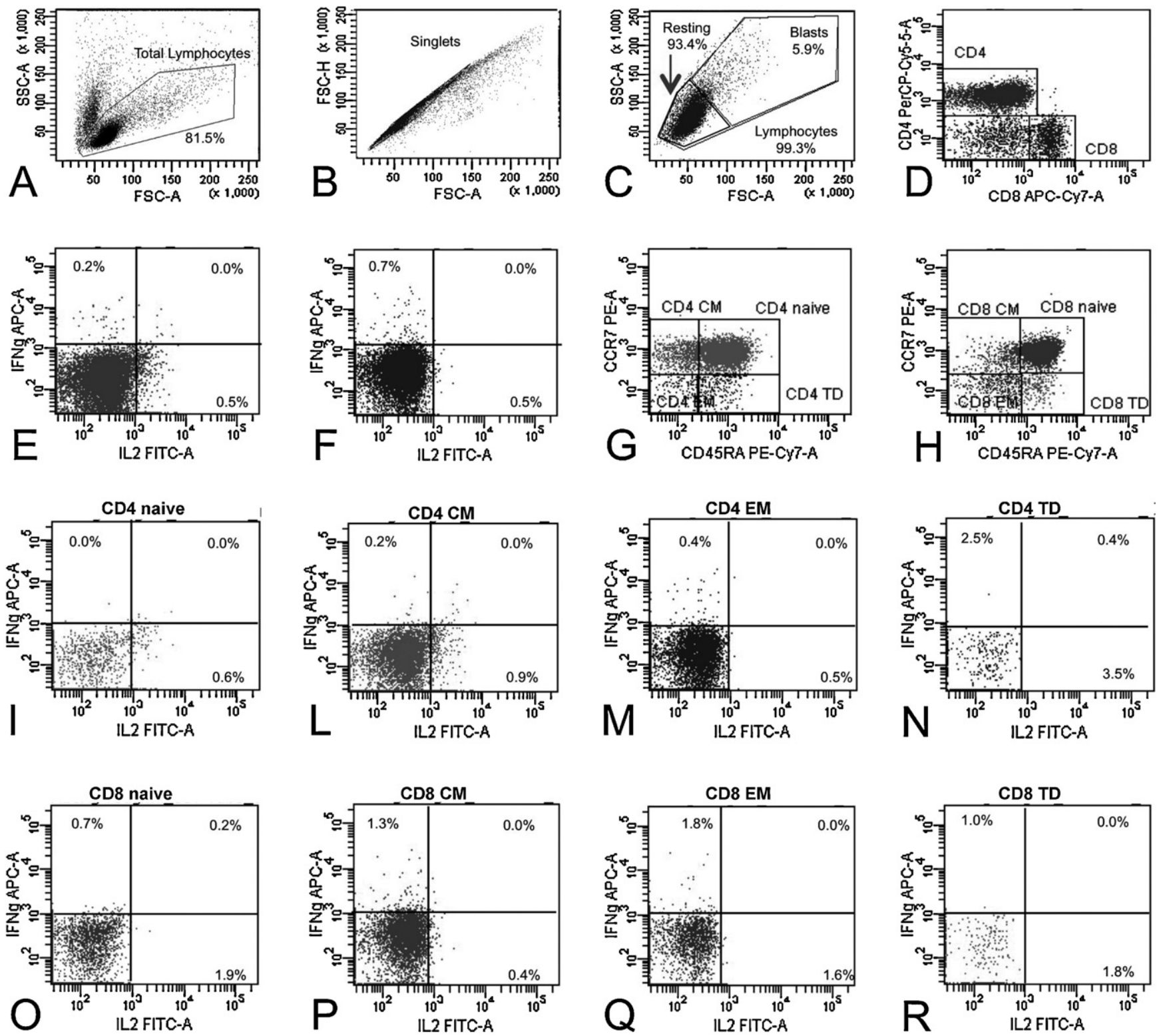

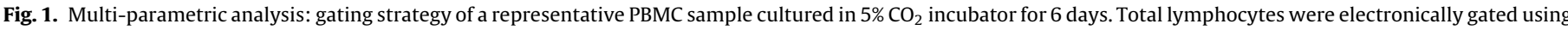

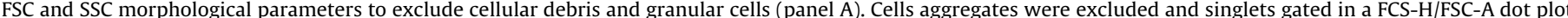

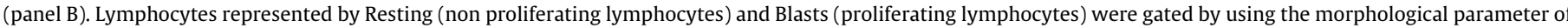

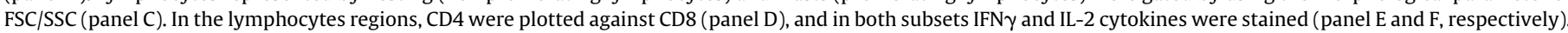

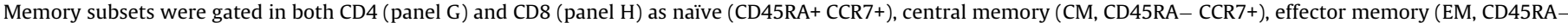
CCR7-) and terminally differentiated (TD, CD45RA+ CCR7-). IFN $\gamma$ and IL-2 were measured in each single memory subsets as for CD4/CD8 subsets (I-R).

diluted in staining buffer plus $0.5 \%$ saponin. All samples were incubated for $30 \mathrm{~min}$ in the dark at room temperature and washed in staining buffer. Cell acquisition was performed using FACSCanto flow cytometer (Becton Dickinson), following the gating strategy, shown in Fig. 1. For each analysis, 50,000 events were acquired in the CD4 cell gate. Samples were first run using single fluorochrome-stained preparations for colour compensation. The cytometric analysis was performed using DIVA software (Becton Dickinson) and data are shown as \% of positive cells.

\subsection{Statistical analysis}

All data were recorded on a computerized database. Results were reported as mean \pm standard error of the mean (SEM). Statistical analysis was performed using the SPSS 17.0 (SPSS Inc., Chicago,
IL, US). To compare overall differences in the results of the different assays between groups of children receiving Hexavac or Infanrix as their primary vaccination, the $t$ Student unpaired-sample test was performed. To compare overall differences in the different assays within groups, the Wilcoxon paired-samples test was performed. $p$ values less than 0.05 were considered statistically significant and all reported $p$ values were two sided.

\section{Results}

\subsection{HBsAg specific T cell responses in PBMC of Hexavac or Infanrix vaccine recipients}

Fig. 1 shows the HBsAg specific T cell responses in two cohorts of children who received a primary vaccination with either Hexavac or Infanrix. The proliferation data showed that HBsAg specific 

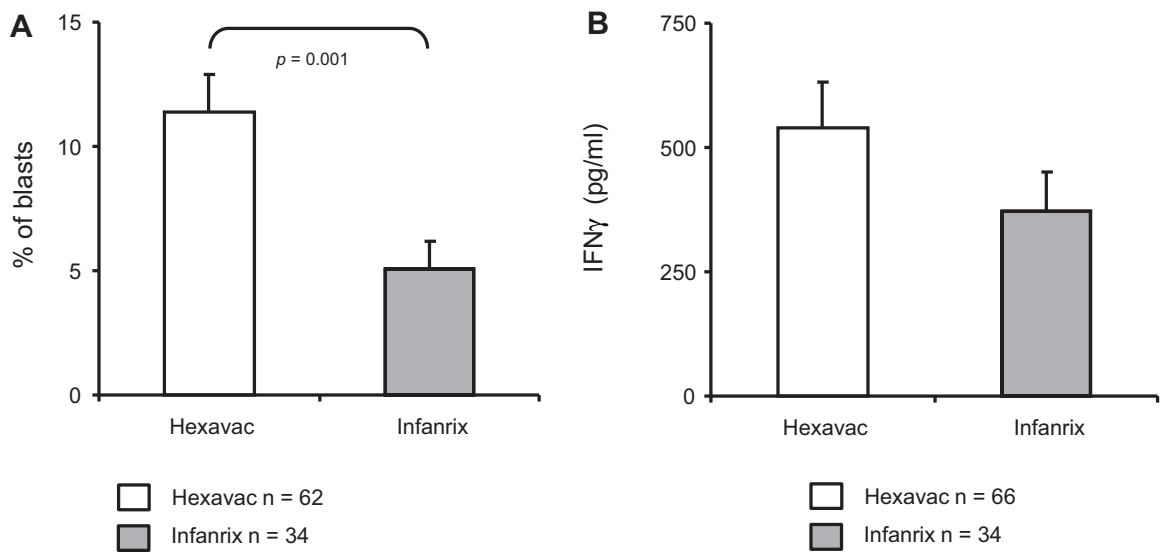

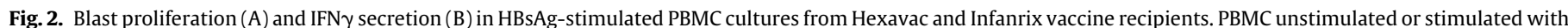

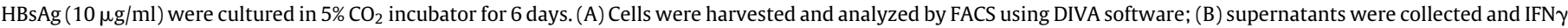

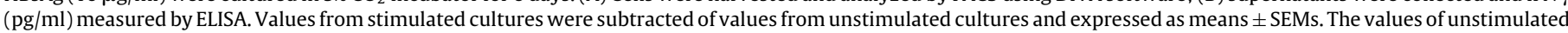

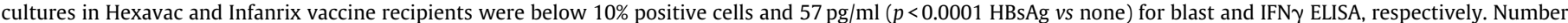

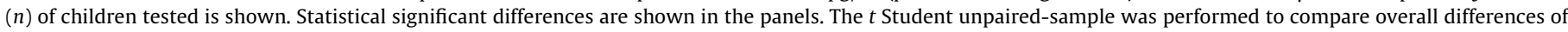
results between the two groups of children. All statistical analysis is two sided.

blast proliferation was significantly higher in the children vaccinated with Hexavac than in those who received Infanrix (Fig. 2A). IFN $\gamma$ secretion supported these results, although the differences between the two groups of vaccines were not statistically significant ( $p=0.239$ ) (Fig. 2B). The PBMC of the two group of children behave similarly when the positive control SEB was used (Table 1).

Serological analysis of the same cohorts had already been performed in a previous companion study on the persistence of $B$ memory response in the same children [15]. As reported in Table 1, anti-HBsAg concentrations were over the recommended cut-of to indicate protection $(10 \mathrm{mIU} / \mathrm{ml})[8]$ in $76 \%$ of the Infanrix recipients but in only $42 \%$ of the Hexavac recipients, thus confirming a previous report in a larger cohort that Infanrix is more efficient in maintaining Ab levels [8]. As shown in Table 2, when blast proliferation and IFN $\gamma$ secretion were analyzed in low $(<10 \mathrm{mIU} / \mathrm{ml})$ or high $(>10 \mathrm{mIU} / \mathrm{ml})$ anti-HBsAg IgG responders, no correlation was found between $\mathrm{Ab}$ response and $\mathrm{T}$ cell response in the two vaccinal arms. Furthermore HBsAg induced blast proliferation and IFN $\gamma$ production are not different in children vaccinated with Hexavac, with low or high humoral responsiveness, as compared to children vaccinated with Infanrix with low or high humoral responsiveness (Table 2).

Measuring the frequency of CD4/CD8 cells secreting IFN $\gamma / \mathrm{IL}-2$ allowed more precise identification of the HBsAg specific T cell producing the cytokines. Fig. 3 shows the results of IFN $\gamma$ and IL-2, measured by intracellular staining (ICS), performed in PBMC cultures obtained from Hexavac or Infanrix recipients. The antigen specific production of both cytokines was statistically higher when measured at day 6 than at day 1 of culture in CD4 and CD8 subsets and in both vaccinal arms. The percentage of poly-functional
IFN $\gamma /$ IL-2 double positive cells was very low in both the CD4 and the CD8 cells, and never reached $0.01 \%$ of positive cells (data not shown).

Both the CD4 and the CD8 subsets produced HBsAg specific cytokines, with CD8 cells generally producing higher cytokine levels than the $\mathrm{CD} 4$ subset. After one day of culture, statistical significance was reached in the percentage of IFN $\gamma$ in CD8 cells vs CD4 cells $(p=0.007)$ from Hexavac recipients, and after six days of culture in the percentage of IL-2 in CD8 cells vs CD4 cells $(p=0.035)$ from Infanrix recipients. These data suggest that beside CD4 subsets [21] also CD8 cells take part to the HBsAg response.

No significant differences in cytokine production were observed between the two vaccinal arms in either the CD4 or the CD8 subsets.

\subsection{T memory subsets in HBsAg stimulated PBMC of Infanrix or Hexavac vaccine recipients}

T cell memory subsets were studied by measuring the expression of the following marker combinations in CD4 and CD8 T cells subsets: CCR7+ CD45RA+ for naïve; CCR7+CD45RA - for CM; CCR7CD45RA - for EM; and CCR7- CD45RA+ for TD cells.

Fig. 4 shows the frequencies of memory subsets tested in CD4 and CD8 cells in HBsAg-stimulated PBMC cultures in the two groups of vaccinated children, measured after 1 or 6 days of culture. In the CD4 cell population, we found lower frequencies of naive cells in Hexavac recipients than in Infanrix recipients, both at day 1 and at day 6. Frequencies of the CM subset at day 6 and of the EM and TD subsets at day 1 were significantly higher in Hexavac than in Infanrix recipients.

Table 2

Blast proliferation and IFN $\gamma$ secretion analyzed in low $(<10 \mathrm{mIU} / \mathrm{ml})$ or high $(>10 \mathrm{mIU} / \mathrm{ml})$ anti-HBsAg IgG responders

\begin{tabular}{|c|c|c|c|c|}
\hline \multirow[t]{3}{*}{ Vaccines } & \multicolumn{2}{|l|}{$\%$ Blasts } & \multicolumn{2}{|l|}{ IFN $\gamma(\mathrm{pg} / \mathrm{ml})$} \\
\hline & $<10 \mathrm{mIU} / \mathrm{ml}$ & $>10 \mathrm{mIU} / \mathrm{ml}$ & $<10 \mathrm{mIU} / \mathrm{ml}$ & $>10 \mathrm{mIU} / \mathrm{ml}$ \\
\hline & Mean \pm SEM & & Mean \pm SEM & \\
\hline $\begin{array}{l}\text { Hexavac } \\
\text { No. children/over the total } \\
t \text { Student unpaired-sample }(p) \text {;Pearson coefficient }(r)\end{array}$ & $\begin{array}{l}12.75 \pm 2.2 \\
35 / 62 \\
p=0.3190\end{array}$ & $\begin{array}{l}9.7 \pm 2.1 \\
27 / 62 \\
r=0.04495\end{array}$ & $\begin{array}{l}472.1 \pm 100.6 \\
38 / 66 \\
p=0.4073\end{array}$ & $\begin{array}{l}629.0 \pm 171.6 \\
28 / 66 \\
r=-0.2060\end{array}$ \\
\hline $\begin{array}{l}\text { Infanrix } \\
\text { No. children/over the total } \\
t \text { Student unpaired-sample }(p) \text {;Pearson coefficient }(r)\end{array}$ & $\begin{array}{l}3.85 \pm 1.0 \\
8 / 34 \\
p=0.5688\end{array}$ & $\begin{array}{l}5.4 \pm 1.4 \\
26 / 34 \\
r=-0.6421\end{array}$ & $\begin{array}{l}280.9 \pm 79.3 \\
8 / 34 \\
p=0.5485\end{array}$ & $\begin{array}{l}398.2 \pm 103.6 \\
26 / 34 \\
r=-0.05537\end{array}$ \\
\hline
\end{tabular}



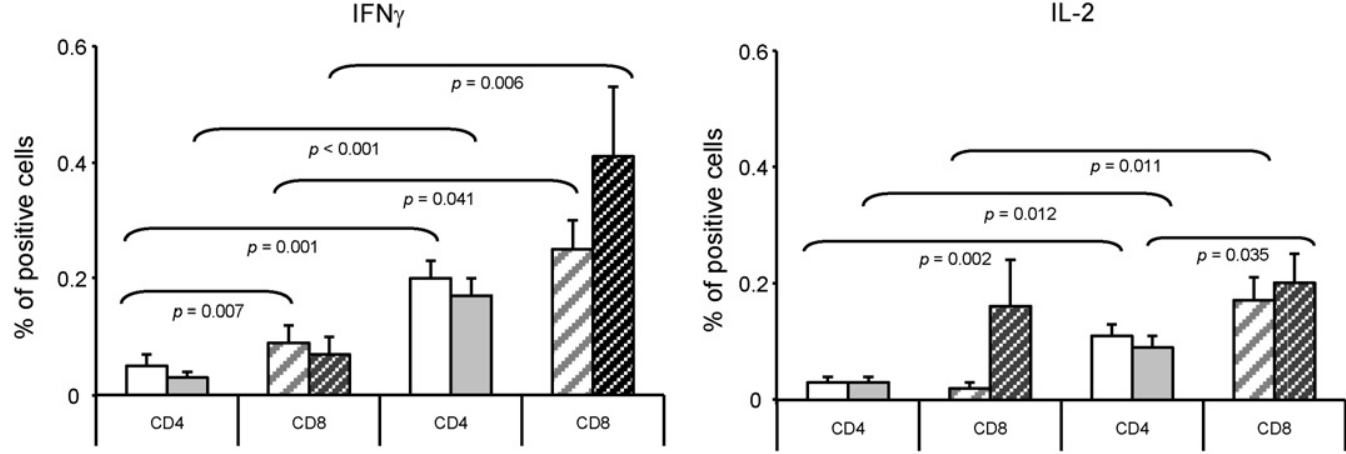

CD4 Hexavac day $1 \mathrm{n}=34$; day $6 n=62$

CD8 Hexavac day $1 n=34$; day $6 n=62$

CD4 Infanrix day $1 \mathrm{n}=34$; day $6 n=34$

$\square \mathrm{CD} 4$ Infanrix day $1 \mathrm{n}=34$; day $6 n=34$

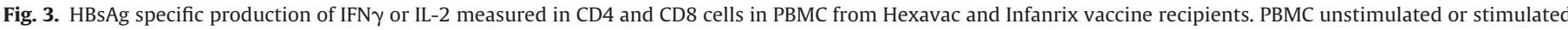

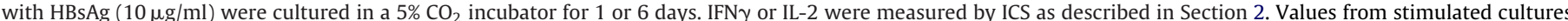

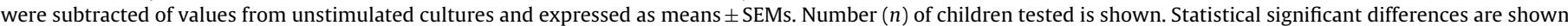

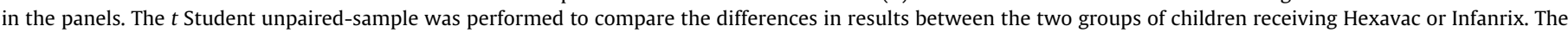

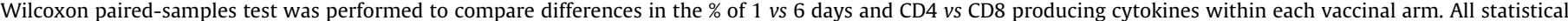
analysis is two sided.

Corresponding results were seen in the CD8 subsets, where the frequencies of naïve cells at day 1 of culture and of $\mathrm{CM}$ at days 1 and 6 were significantly lower in Hexavac than in Infanrix recipients.

Fig. 5 shows HBsAg-induced cytokine production by the memory subsets after 6 days of culture as measured by ICS. A few significant differences were found in cytokine production between the two vaccinal arms, namely more IFN $\gamma$ producing cells in CD4 TD and fewer IFN $\gamma$ producing cells in CD8 naive cells in Hexavac than in Infanrix recipients. In the $\mathrm{CM}$ subsets alone, $\mathrm{CD} 8$ cells proved more efficient at producing cytokines than CD4 cells, independently of the vaccine used.

Although the percentage of cells producing cytokines is quite limited and the data should be interpreted with caution, taken together, these results indicate that the expansion of memory subsets and CD4 TD producing IFN $\gamma$ is higher in Hexavac than in Infanrix recipients. This corresponds to the enhanced proliferative response observed in PBMC obtained from Hexavac recipients.

\section{Discussion}

Our data indicate that two vaccines generating different serum Ab levels can both induce $T$ antigen specific responses in vitro, five years after primary vaccination.

The less immunogenic Hexavac vaccine, measured by $\mathrm{HB}$ serological response, induces a stronger $\mathrm{T}$ antigen response
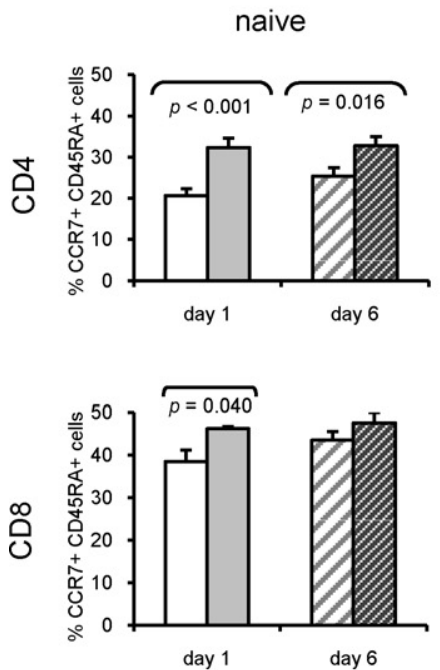

Hexavac day $1 \mathrm{n}=34$ Infanrix day $1 \mathrm{n}=34$
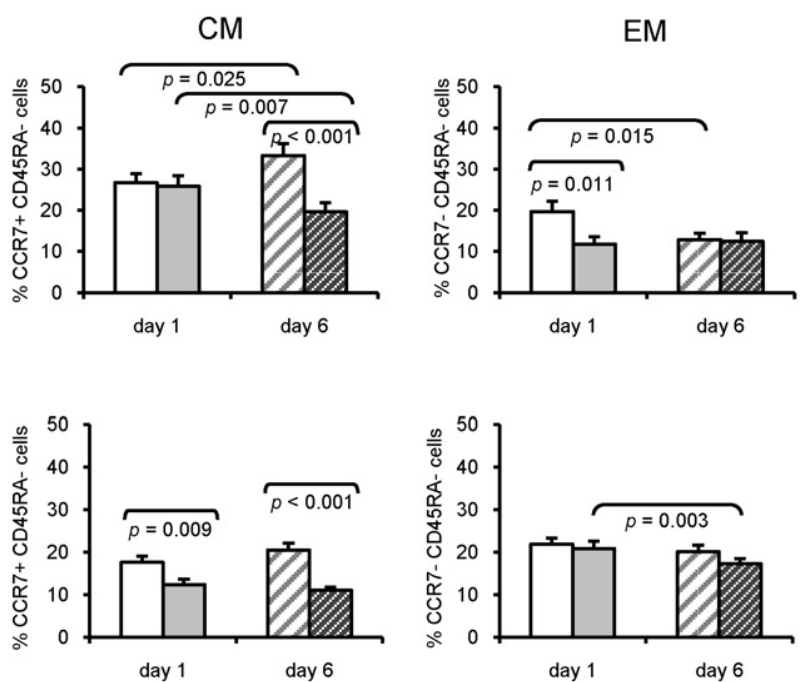

Hexavac day $6 n=62$

$\mathscr{Z}$ Infanrix day $6 n=34$

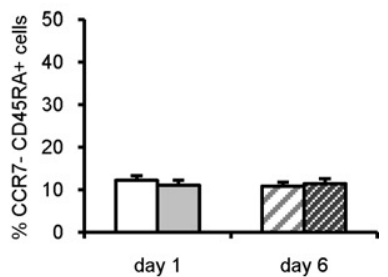

EM

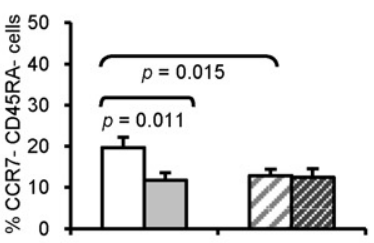

day 1

day 6

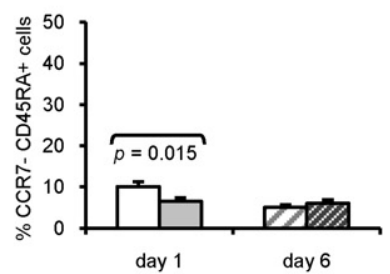

day

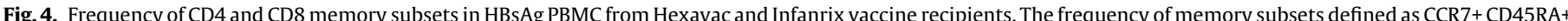

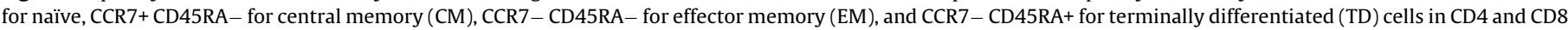

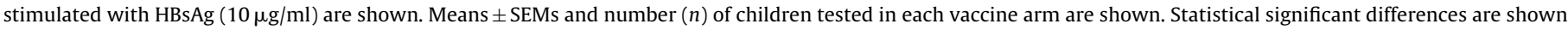

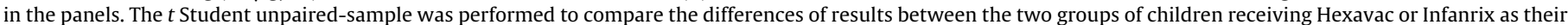

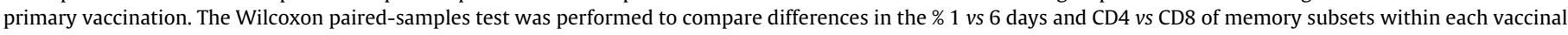
arm. All statistical analysis is two sided. 
naive
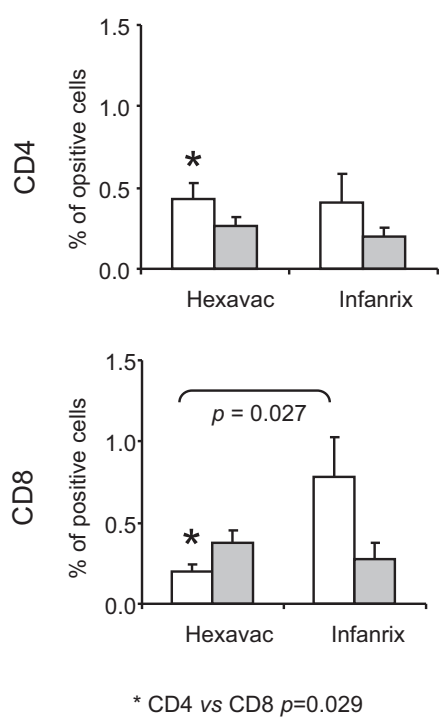

CM
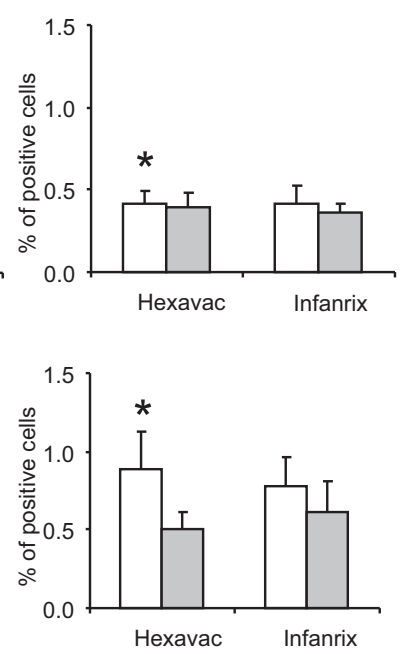

${ }^{*}$ CD4 vs CD8 $p=0.049$
EM
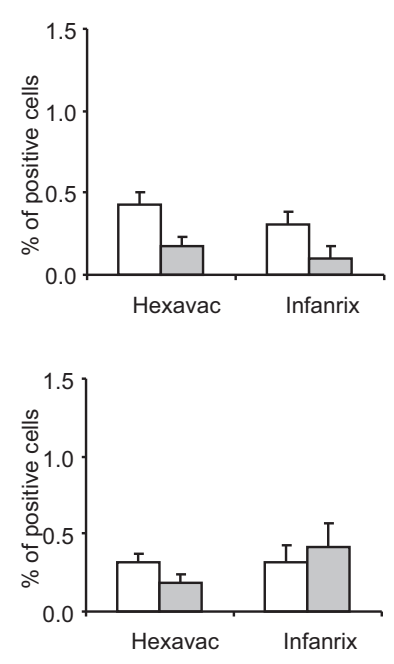

Infanrix $\mathrm{n}=34$
TD
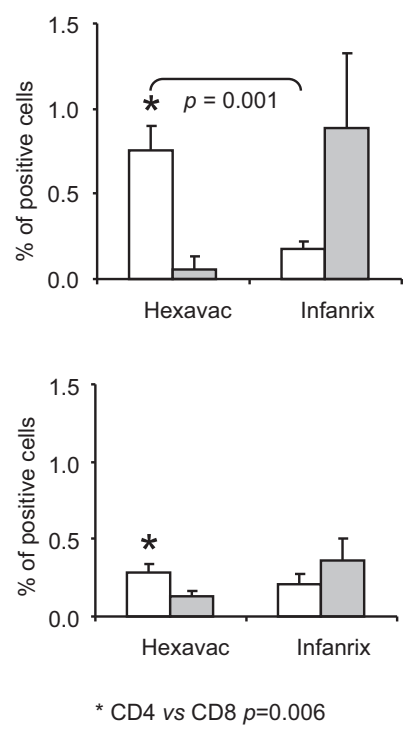

IFN $\gamma$

IL-2

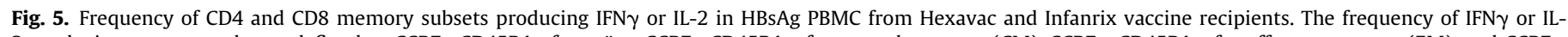

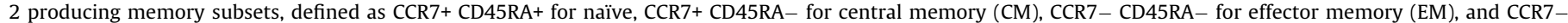

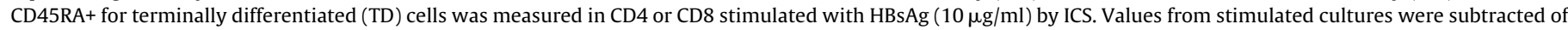

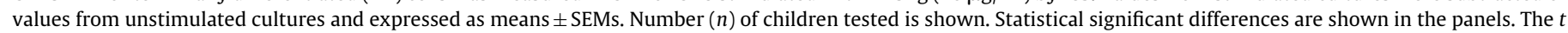

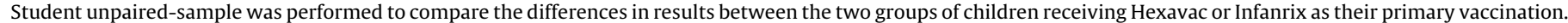

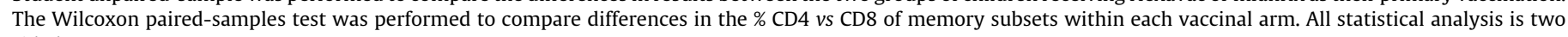
sided.

than the Infanrix vaccine, as evidenced by an increased blast proliferation and the overall enhanced presence of memory subsets in HBsAg stimulated cultures. HBsAg induced $\mathrm{T}$ cell responses are not different in children vaccinated with Hexavac or Infanrix vaccines with low or high humoral responsiveness.

These results correlate well with those from a previous study revealing the maintenance of switched memory $B$ cells in the same cohort of Hexavac vaccine recipients [15]. They are also in agreement with evidence from study of a larger cohort showing that Hexavac and Infanrix recipients are equally capable of mounting an efficient serological HB specific Ab response after in vivo recall stimulation, elicited by the administration of a booster dose of antihepatitis vaccine [8].

CD4T helper cells are an essential component of immunological response. They control secondary immune reactions and provide critical signals to B cells [22,23] and CD8 cytotoxic T cells [24], reacting to the same antigen. We compared the persistence of memory response 5 years after the primary hepatitis vaccination by evaluating the HBsAg recall response in all T cells and in the CD4 and CD8 subsets. As a first step, we analyzed the ability of HBsAg to expand T cells in both vaccine groups, finding that HBsAg induced a significantly higher percentage of blast proliferation in Hexavac recipients than in Infanrix recipients. The secretion of IFN $\gamma$ paralleled the results of proliferation, although the differences never reached statistical significance (Fig. 2). HBsAg-induced cytokine production was greater in CD8 than in CD4 cells in both vaccinal arms, although the differences were not always statistically significant. This is in agreement with the dominant role of CD8 in HbsAg-induced response [25]. It has been shown that peripheral blood-derived dendritic cells actively take up soluble HBsAg and, via a MHC class I cross-presentation pathway, elicit CD8 responses [26].
Virus-specific CD8T cells did not develop in CD4-deficient animals, consistent with a model where CD4T cells serve as master regulators of the adaptive immune response to HBV. In turn, CD8T cells were the key cellular effectors mediating HBV clearance from the liver, apparently by a Fas-dependent, perforin-independent process [27].

After HBsAg stimulation, we found a significantly lower frequency of naive cells both at days 1 and 6, paralleled by a higher increase in CM frequencies at day 6 of cultures in Hexavac than in Infanrix recipients; the frequency of EM and TD found at day 1 in CD4 cells also tended to be higher in Hexavac than in Infanrix recipients (Fig. 4). In line with these results, we also found significantly higher CD4 TD cells producing IFN $\gamma$ in Hexavac than in Infanrix recipients (Fig. 5). What is not understood is why we did not find a greater expansion of EM and TD cells after antigenic stimulation as other authors did, albeit in different experimental settings [28-31]. In our experimental setting, the analysis of memory subsets was performed in all T cells and not only in activated/proliferating ones. An activation marker such as CD69, identified as the earliest activation marker on antigen specific activated lymphocytes [32], could allow more precise definition of the responsive cells.

Taken together, these results suggest that immunological memory of Hexavac recipients is more active in expanding memory subsets when $\mathrm{T}$ cells are specifically stimulated with HBsAg. The most apparent difference between Hexavac and Infanrix is the amount of HBsAg in a vaccine dose, but both vaccines had complex hexavalent formulation. Further studies are necessary to identify the key element/s that modulate the differences in $\mathrm{T}$ cells responses between the two vaccines.

This is the first study analyzing the memory pool subsets specific for HBsAg. Our results indicate that CD4 and CD8 CM cell levels are higher in Hexavac than in Infanrix recipients, which may reflect the ability of $\mathrm{T}$ cells to readily proliferate in response to antigenic 
stimulation. This interpretation is in keeping with the enhanced ability of HBsAg activated PBMC to proliferate and secrete IFN $\gamma$ in the cultures found in these vaccinated children.

This study on the analysis of T memory pool, along with its companion on the analysis of the $B$ memory pool performed in the same cohort of children [15], demonstrates that the T and B cell components of immune response are not highly correlated with the level of serum $\mathrm{Ab}$.

There is no evidence at this time indicating that absent or low serum conversion after vaccination (as with subjects who did not become serum positive after HBV vaccination) coincides with vaccine failures or outbreaks of hepatitis $[5,7,33,34]$. Thus, it could be assumed that the cell-based immunity induced by vaccination is adequate protection from HBV infection. Nonetheless, the specific contribution of the $\mathrm{T}$ cell compartment in Hexavac low $\mathrm{Ab}$ responders warrants further study. Indeed, few studies have hypothesized an increased frequency of regulatory $T$ cells involved in the low rate of HBV seroconversion $[35,36]$. We did not evaluate regulatory $\mathrm{T}$ cells in our cohort, and this could be the subject for further study.

Here we demonstrate that immunological memory persists five years after primary vaccination in children with anti-HBsAg concentrations lower than $10 \mathrm{mIU} / \mathrm{ml}$, suggesting that booster doses are not required. However, follow-up studies should be conducted to determine whether this protection is long-term and maintained in adolescence and adulthood.

Our data suggest that cellular parameters should be considered along with serological indicators as surrogate markers of protection. Demonstration of the persistence of memory response in the individual vaccine remains a challenge, especially when the anti-HB Abs have disappeared, apart from the possibility to revaccinate and look for an anamnestic response [37]. The assessment of $\mathrm{T}$ cell recall responses could be a useful adjunct in demonstrating the persistence of a memory response. This would provide valuable input to health authorities, such us the European Medicines Agency, as they evaluate new vaccination strategies and make critical decisions with potential implications for health systems and economies at both the national and supranational levels.

\section{Acknowledgements}

The authors thank all of the children and their families, whose collaboration made this study possible. The authors also thank the study group: A.R. Zanetti (University of Milan, Milan); C. Giambi, F. D'Ancona, E. Madonna, M. Rapicetta, S. Salmaso (Istituto Superiore di Sanità, Rome); M.L. Ciofi Degli Atti (Bambino Gesù Paediatric Research Hospital, Rome). We thank Simonetta Pietrangeli for technical support and Laura McLean for help in revising and editing our English. This study was supported by grants from AIFA (Agenzia Italiana del Farmaco, code FAM67NFPN), from the European Commission under grant agreement \#201502 (ChildINNOVAC) and by the Italian Ministry of Health, CCM (1M51, 1M63). The funders had no role in study design, data collection and analysis, decision to publish, or in preparation of the manuscript.

\section{References}

[1] Chang MH, Shau WY, Chen CJ, Wu TC, Kong MS, Liang DC, et al. Hepatitis $B$ vaccination and hepatocellular carcinoma rates in boys and girls. JAMA 2000;284:3040-2.

[2] Rehermann B, Nascimbeni M. Immunology of hepatitis B virus and hepatitis C virus infection. Nat Rev Immunol 2005;5:215-29.

[3] Herkel J, Carambia A. Let it B in viral hepatitis? J Hepatol 2011;55:5-7.

[4] Lemon SM, Thomas DL. Vaccines to prevent viral hepatitis. N Engl J Med 1997;336:196-204.
[5] Huang LM, Lu CY, Chen DS. Hepatitis B virus infection, its sequelae, and prevention by vaccination. Curr Opin Immunol 2011;23:237-43.

[6] Scientific conclusions and grounds for the suspension of the marketing authorisation of Hexavac presented by the EMEA. http://ema.europe.eu/ humandocs/PDFs/EPAR/Hexavac/Hexavac-H-298-Z-28-en.pdf

[7] Jorgensen P, Poethko-Müller C, Hellenbrand W, Jilg W, Thierfelder W, Meyer C, et al. Low hepatitis B immunogenicity of a hexavalent vaccine widely used in Germany: results of the German Health Survey for Children and Adolescents, 2003-2006. Epidemiol Infect 2010;138:1621-9.

[8] Zanetti AR, Romanò L, Giambi C, Pavan A, Carnelli V, Baitelli G, et al. Hepatitis $\mathrm{B}$ immune memory in children primed with hexavalent vaccines and given monovalent booster vaccines: an open-label, randomised, controlled, multicentre study. Lancet Infect Dis 2010;10:755-61.

[9] Zielinski CE, Corti D, Mele F, Pinto D, Lanzavecchia A, Sallusto F. Dissecting the human immunologic memory for pathogens. Immunol Rev 2011;240:40-51.

[10] Zhou X, McElhaney JE. Age-related changes in memory and effector T cells responding to influenza $\mathrm{A} / \mathrm{H} 3 \mathrm{~N} 2$ and pandemic $\mathrm{A} / \mathrm{H} 1 \mathrm{~N} 1$ strains in humans. Vaccine 2012;29:2169-77.

[11] Sallusto F, Lanzavecchia A. Memory in disguise. Nat Med 2010;17:1182-3.

[12] Lanzavecchia A, Sallusto F. Understanding the generation and function of memory T cell subsets. Curr Opin Immunol 2005;17:326-32.

[13] Sallusto F, Kremmer E, Palermo B, Hoy A, Ponath P, Qin S, et al. Switch in chemokine receptor expression upon TCR stimulation reveals novel homing potential for recently activated T cells. Eur J Immunol 1999;29:2037-45.

[14] Harari A, Vallelian F, Pantaleo G. Phenotypic heterogeneity of antigen-specific CD4T cells under different conditions of antigen persistence and antigen load Eur J Immunol 2004;34:3525-33.

[15] Rosado MM, Scarsella M, Pandolfi E, Cascioli S, Giorda E, Chionne P, et at. Switched memory B cells maintain specific memory independently of serum antibodies: the hepatitis B example. Eur J Immunol 2011;41:1800-8.

[16] Ausiello CM, Lande R, Urbani F, Di Carlo B, Stefanelli P, Salmaso S, et al. Cellmediated immunity and antibody responses to Bordetella pertussis antigens in children with a history of pertussis infection and in recipients of an acellular pertussis vaccine. J Infect Dis 2000;181:1989-95.

[17] Carollo M, Palazzo R, Bianco M, Smits K, Mascart F, Ausiello CM. Antigen-specific responses assessment for the evaluation of Bordetella pertussis T cell immunity in humans. Vaccine 2012;30:1667-74.

[18] Cosmi L, Maggi L, Santarlasci V, Liotta F, Frosali F, Angeli R, et al. Detection by flow cytometry of ESAT-6- and PPD-specific circulating CD4+ T lymphocytes as a diagnostic tool for tuberculosis. Int Arch Allergy Immunol 2007;143:1-9.

[19] Palazzo R, Spensieri F, Massari M, Fedele G, Frasca L, Carrara S, et al. Use of whole-blood samples in in-house bulk and single-cell antigen-specific gamma interferon assays for surveillance of Mycobacterium tuberculosis infections. Clin Vaccine Immunol 2008;15:327-37.

[20] Wilkinson TM, Li CK, Chui CS, Huang AK, Perkins M, Liebner JC, et al. Preexisting influenza-specific CD4+ T cells correlate with disease protection against influenza challenge in humans. Nat Med 2012;18:274-8.

[21] Honorati MC, Dolzani P, Mariani E, Piacentini A, Lisignoli G, Ferrari C, et al. Epitope specificity of Th0/Th2 CD4+ T-lymphocyte clones induced by vaccination with rHBsAg vaccine. Gastroenterology 1997;112:2017-27.

[22] Gourley TS, Wherry EJ, Masopust D, Ahmed R. Generation and maintenance of immunological memory. Semin Immunol 2004;16:323-33.

[23] Bussmann BM, Reiche S, Bieniek B, Krznaric I, Ackermann F, Jassoy C. Loss of HIV-specific memory B-cells as a potential mechanism for the dysfunction of the humoral immune response against HIV. Virology 2010;397:7-13.

[24] Sun JC, Bevan MJ. Defective CD8T cell memory following acute infection without CD4T cell help. Science 2003;300:339-42.

[25] Barber DL, Wherry EJ, Masopust D, Zhu B, Allison JP, Sharpe AH, et al. Restoring function in exhausted CD8T cells during chronic viral infection. Nature 2006:439:682-7.

[26] Op den Brouw ML, Binda RS, van Roosmalen MH, Protzer U, Janssen HL, van der Molen RG, et al. Hepatitis B virus surface antigen impairs myeloid dendritic cell function: a possible immune escape mechanism of hepatitis B virus. Immunology 2009;126:280-9.

[27] Yang PL, Althage A, Chung J, Maier H, Wieland S, Isogawa M, et al. Immune effectors required for hepatitis B virus clearance. Proc Natl Acad Sci USA 2009; 107:798-802.

[28] Cruz SC, Souza SL, Cruz AC, Silva GP, Milagres LG. Human antibody and memory $\mathrm{B}$ and T-cell responses after primary and booster immunisation against Neisseria meningitidis B. Vaccine 2011;29:7387-94.

[29] Barbey C, Pradervand E, Barbier N, Spertini F. Ex vivo monitoring of antigenspecific CD4+ T cells after recall immunization with tetanus toxoid. Clin Vaccine Immunol 2007; 14:1108-16.

[30] Kaveh DA, Bachy VS, Hewinson RG, Hogarth PJ. Systemic BCG immunization induces persistent lung mucosal multifunctional CD4 T(EM) cells which expand following virulent mycobacterial challenge. PLoS One 2011;6:e21566.

[31] Bauer T, Jilg W. Hepatitis B surface antigen-specific T and B cell memory in individuals who had lost protective antibodies after hepatitis B vaccination. Vaccine 2006;24:572-7.

[32] Testi R, D'Ambrosio D, De Maria R, Santoni A. The CD69 receptor: a multipurpose cell-surface trigger for hematopoietic cells. Immunol Today 1994:15:479-83.

[33] Ni YH, Huang LM, Chang MH, Yen CJ, Lu CY, You SL, et al. Two decades of universal hepatitis B vaccination in taiwan: impact and implication for future strategies. Gastroenterology 2007;132:1287-93.

[34] Craven DE, Awdeh ZL, Kunches LM, Yunis EJ, Dienstag JL, Werner BG et al. Nonresponsiveness to hepatitis B vaccine in health care workers. 
Results of revaccination and genetic typings. Ann Intern Med 1986:105: $356-60$.

[35] del Pozo Balado Mdel M, Leal M, Méndez Lagares G, Mata RC, LópezCortés LF, Viciana P, et al. Increased regulatory T cell counts in HIV-infected nonresponders to hepatitis B virus vaccine. J Infect Dis 2010;202: $362-9$.
[36] Yang Z, Wang L, Niu W, Wu Y, Zhang J, Meng G. Increased CD4+ CD25+ FoxP3+ regulatory $T$ cells in the blood of nonresponders after standard hepatitis $B$ surface antigen vaccine immunization. Clin Immunol 2008;127:265-6.

[37] Giambi C, Bella A, Barale A, Montù D, Marchisio M, Oddone M, et al. A cohort study to evaluate persistence of hepatitis B immunogenicity after administration of hexavalent vaccines. BMC Infect Dis 2008;28:100-07. 